\title{
Price asymmetry between different pork cuts in the USA: a copula approach
}

\author{
Dimitrios Panagiotou* and Athanassios Stavrakoudis
}

\author{
*Correspondence: \\ dpanag@cc.uoi.gr \\ Department of Economics, \\ University of loannina, loannina, \\ Greece
}

\begin{abstract}
The objective of this study is to assess the degree and the structure of price dependence between different cuts in the US pork industry at the retail level. To this end, it utilizes monthly retail data of pork cuts and the statistical tool of copulas. The empirical results suggest that for all pairs, retail prices are not likely neither to boom nor to crash together, even though overall dependence is quite considerable for two of the three pairs considered in this study. No evidence of asymmetric price co-movements was found.
\end{abstract}

Keywords: Price asymmetry; Pork cuts; Copula

\section{Background}

Pork consumers are more conscientious about specific quality characteristics of their meat than they were before. Fat content, tenderness, appearance, juiciness, are just some of the characteristics that most of the consumers take into account when purchasing pork, apart from the price. Despite this fact, most of the studies about the U.S. pork industry have been carried out considering aggregate commodity prices, and treating the pork product as a non-differentiated good.

Against this background, the objective of this paper is to investigate if the existence of product differentiation could be a source of asymmetric price co-movements between certain pork cuts at the retail level. Preference for specific cuts implies that consumers have different marginal willingness to pay for these different pork products. Consequently, their response might be different when prices change. Simultaneously, retailers/wholesalers can price discriminate based on the different attributes of the commodity. This means that sellers might adopt different pricing strategies, depending on the cut, when market conditions change. Conclusively, estimating price dependence while considering pork as a non-differentiated product, would ignore differential responses. Empirical results may not capture the actual pricing behavior.

Price asymmetry has been an important topic in agricultural and food economics over a long period of time, since it may be an indicator of market inefficiency. As such, it attracts the attention of economists and policy-makers.

Boyd and Brorsen (1988) tested for asymmetry in price adjustments and the speed of price adjustments in the pork marketing channel. Results show that wholesale prices

(c) 2015 Panagiotou and Stavrakoudis; licensee Springer. This is an Open Access article distributed under the terms of the Creative Commons Attribution License (http://creativecommons.org/licenses/by/4.0), which permits unrestricted use, distribution, and reproduction in any medium, provided the original work is properly credited. 
respond symmetrically to farm price decreases and increases. Additionally, there was no significant difference between retailers' response to wholesale price increases and their response to wholesale price decreases.

Goodwin and Harper (2000) used a threshold co-integration model that permits asymmetric adjustment to positive and negative price shocks. Their results reveal important asymmetries. Price adjustment patterns are unidirectional, and information tends to flow from farm, to wholesale, to retail markets.

In our study, we empirically estimate retail price dependence between different pork cuts, utilizing the statistical tool of copulas. Copulas offer an alternative way to analyse price co-movements, particularly during extreme market events.

Copulas are quite popular in finance and risk management since the late 1990s, but only recently have gained momentum in agricultural economics. Emmanouilides et al. (2013), assessed price dependence in the olive oil market of the Mediterranean (Greece, Spain, and Italy). Reboredo (2012) examined co-movement between international food (corn, soya beans and wheat) and oil prices.

Regarding the pork industry, (Qiu and Goodwin 2012) estimated asymmetric price transmission in the hog supply chain using copulas (case of vertical transmission). Their results indicate evidence of symmetry and asymmetry. For the farm to wholesale and wholesale to retail marketing chains, shocks in one market would transfer to the other market. For the farm to retail case, retail prices do not respond to price reduction in farm level prices.

To the best of our knowledge, there has been no published work which has examined retail price co-movements between different pork cuts with the use of copulas.

The present work is structured as follows: Section "Methods" contains the theoretical framework. Section "Results and Discussion" presents the empirical models and the results. Section "Conclusions" offers conclusions.

\section{Methods}

Copula theory dates back to (Sklar 1959), but only recently copula models have realized widespread application in empirical models of joint probability distributions (see (Cherubini et al. 2004; Jaworski et al. 2010; Nelsen 2006) for more details). The models use a copula function to tie together two marginal probability functions that may or may not be related to one another.

A two-dimensional copula, $C\left(u_{1}, u_{2}\right)$, is a multivariate distribution function in the unit hypercube $[0,1]^{2}$ with uniform $\mathrm{U}(0,1)$ marginal distributions ${ }^{\mathrm{a}}$. As long as the marginal distributions are continuous, a unique copula is associated with the joint distribution, $\mathrm{H}$, and is described in equation 1 . This function constitutes a form of the principal result of copula theory (Sklar's theorem). It is obtained as:

$$
C\left(u_{1}, u_{2}\right)=H\left(H_{1}^{-1}\left(u_{1}\right), H_{2}^{-1}\left(u_{2}\right)\right)
$$

Similarly, given a two-dimensional copula, $C\left(u_{1}, u_{2}\right)$, and two univariate distributions, $H_{1}(x)$ and $H_{2}(x)$, equation 1 is a two-variate distribution function with marginals $H_{1}(x)$ and $H_{2}(x)$, whose corresponding density function can be written as:

$$
h(x, y)=c\left(H_{1}(x), H_{2}(y)\right) h_{1}(x) h_{2}(y)
$$


where the functions $h_{1}$ and $h_{2}$ are the densities of the distribution functions $H_{1}$ and $H_{2}$ respectively.

The density function of the copula, c, given its existence, can be derived using equation 1 and marginal density functions, $h_{i}$ :

$$
c\left(u_{1}, u_{2}\right)=\frac{h\left(H_{1}^{-1}\left(u_{1}\right), H_{2}^{-1}\left(u_{2}\right)\right)}{h_{1}\left(H_{1}^{-1}\left(u_{1}\right)\right) h_{2}\left(H_{2}^{-1}\left(u_{2}\right)\right)}
$$

A rank based test of functional dependence is Kendall's tau. It provides information on co-movement across the entire joint distribution function, both at the centre and at the tails of it. It is calculated from the number of concordant $\left(P_{N}\right)$ and disconcordant $\left(Q_{N}\right)$ pairs of observations in the following way:

$$
\tau_{N}=\frac{P_{N}-Q_{N}}{\left(\begin{array}{c}
N \\
2
\end{array}\right)}=\frac{4 P_{N}}{N(N-1)}-1
$$

Often though, information concerning dependence at the tails (at the lowest and the highest ranks) is extremely useful for economists, managers and policy makers. Tail (extreme) co-movement is measured by the upper, $\lambda_{U}$, and the lower, $\lambda_{L}$, dependence coefficients, such that $\lambda_{U}, \lambda_{L} \in[0,1]$, which are defined as

$$
\begin{aligned}
& \lambda_{U}=\lim _{u \uparrow 1} \operatorname{prob}\left(U_{1}>u \mid U_{2}>u\right)=\lim _{u \rightarrow 1} \frac{1-2 u+C(u, u)}{1-u} \\
& \lambda_{L}=\lim _{u \downarrow 0} \operatorname{prob}\left(U_{1}<u \mid U_{2}<u\right)=\lim _{u \rightarrow 0} \frac{C(u, u)}{u}
\end{aligned}
$$

where, given the random vector $(\mathrm{X}, \mathrm{Y})$ with marginal distribution, $U_{1}$ for $\mathrm{X}$ (resp. $U_{2}$ for $\mathrm{Y}), \lambda_{U}$ measures the probability that $X$ is above a high quantile given that $Y$ is also above that high quantile, while $\lambda_{L}$ measures the probability that $X$ is below a low quantile given that $Y$ is also below that low quantile. In order to have upper or lower tail dependence, $\lambda_{U}$ or $\lambda_{L}$ need to be strictly positive. Otherwise, there is upper or lower tail independence. Hence, the two measures of tail dependence provide information about the likelihood for the two random variables to boom and to crash together.

In this study, we consider a range of bivariate copula specifications. All of them are members of the elliptical copulas and Archimedean copulas, since they permit considerable flexibility in capturing retail price dependence between different cuts of pork in the US. Elliptical and Archimedean copulas are the two of the most commonly used copula families. The elliptical copulas that we evaluate are the Gaussian and Student-t. Among the one parameter Archimedean copulas we consider there are the Clayton, Gumbel, Frank, and Joe. Clayton-Gumbel, and Joe-Clayton are among the twoparameter Archimedean copulas we examine.

Table 1 presents the copulas under consideration in our study, their respective dependence parameters, and their relationship to Kendall's tau as well as to upper and lower dependence coefficients $\left(\lambda_{U}\right.$ and $\left.\lambda_{L}\right)$. 
Table 1 Copulas functions, parameters, Kendall's $\tau$, and tail dependence

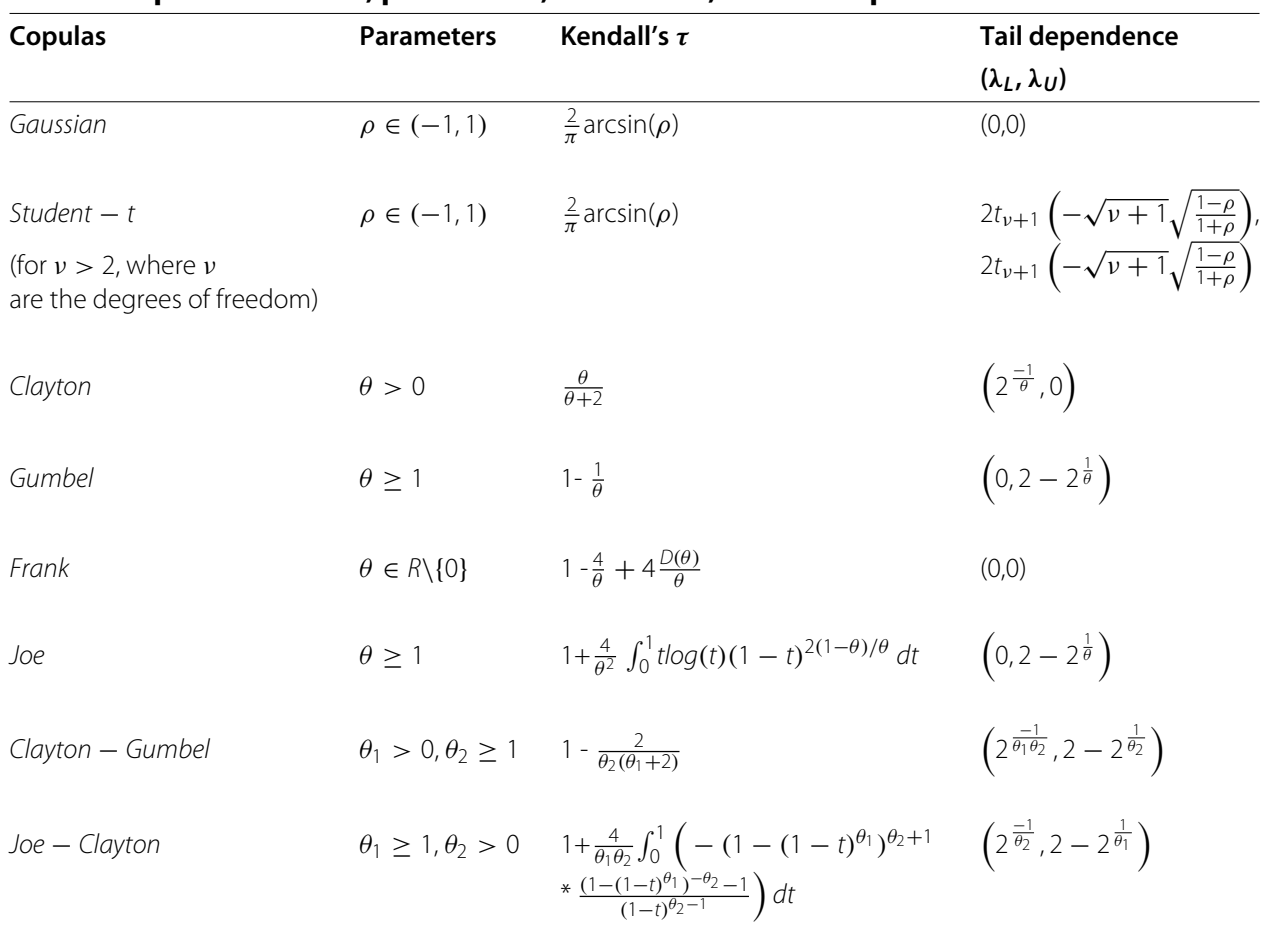

\section{Results and Discussion}

The data for the empirical analysis are monthly retail prices on three pork chop cuts: centre cut - bone in, boneless, and other pork chops. Observations refer to the period 2000:1 to 2014:5, and have been obtained from the Economic Research Service of the United Stated Department of Agriculture (ERS-USDA 2014). Figure 1 presents the price series for the different cuts.

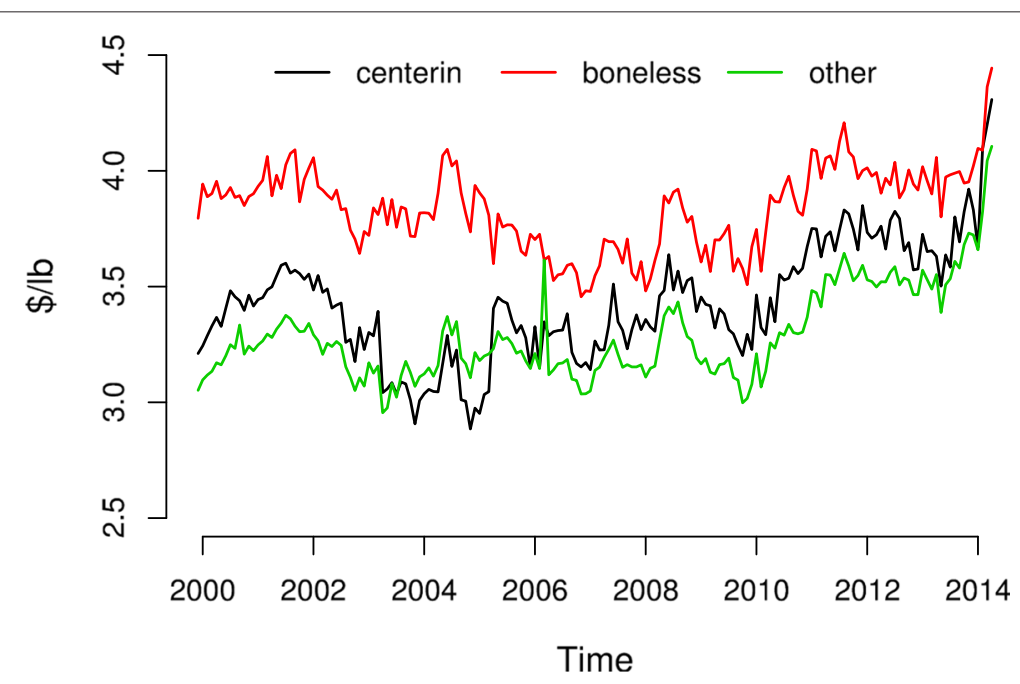

Figure 1 Time series of pork cuts prices: center cut - bone in chops (centerin), boneless chops (boneless) and other pork chops (other). 
Regarding the empirical implementation, we employ the semi-parametric approach proposed by (Chen and Fan 2006) which involves three steps: (a) an Autoregressive Moving Average - Generalized Autoregressive Conditional Heteroskedasticity (ARMAGARCH) model is fit to each series of the rates of price change ${ }^{\mathrm{b}}$. (b) The obtained standardized residuals (filtered data) are then used to calculate the respective empirical distribution functions, creating this way the copula data (c) The estimation of copula models is conducted by applying the maximum likelihood (ML) estimator to the copula data (Canonical ML).

To obtain the filtered rates of price change, an ARMA(p,q) - $\operatorname{GARCH}(1,1)$ model has been fit to each of the innovation series. Selection among different models was made based on Akaike Information Criterion (AIC). The chosen model was the one that gave us the lower AIC value. For the centre cut - bone in series an $\operatorname{ARMA}(2,2)-\operatorname{GARCH}(1,1)$ was picked. For the boneless series as well as the other chops series an $\operatorname{ARMA}(1,1)-$ $\operatorname{GARCH}(1,1)$ was selected ${ }^{c}$. The obtained standardized residuals were then used to calculate the respective empirical distribution functions, creating this way the copula data.

Figure 2 presents the scatter plots of the copula data for the three different pairs of pork cuts.

In the last step, we applied the maximum likelihood estimator to each of the three pairs considered in our study, using the copula data as input.

Table 2 presents the selected copulas with their associated parameters, and the estimates for Kendall's $\tau$, as well as for the lower and upper tail dependence coefficients $\left(\lambda_{L}, \lambda_{U}\right)$.

For the pair bone-in-chops/boneless chops, Kendall's $\tau$ is 0.169 , suggesting a limiting degree of dependence over the entire joint distribution. The pair under consideration is described by the Student-t copula. The estimated lower and upper tail dependence coefficients $\left(\lambda_{L}, \lambda_{U}\right)$ are not statistically significant, indicating that a strongly positive (negative) rate of price change in one of the cuts will not be matched with a comparably strong positive (negative) rate of price change in the other cut. The pairs bone-in-chops/other chops and boneless chops/other chops are described by the Frank copula. Frank copulas exhibit zero value for the lower tail and upper tail coefficients. Kendall's $\tau$ is 0.523 for the former and 0.441 for the latter, revealing that the overall strength of the price dependence between the cuts of the two pairs is quite considerable. On the other hand, the estimated lower and upper tail coefficients are zero in both pairs. These empirical findings suggest that price booms (crashes) in one cut will not be associated with price booms (crashes) in the other cut, for the pairs bone-in-chops/other chops and boneless chops/other chops.

\section{Conclusions}

Price asymmetry has been an important topic in agricultural and food economics, since it may be an indicator of market inefficiency. Most of the existing studies on the U.S. food industry have been carried out considering aggregate commodity prices. In this article we are interested in assessing the degree and the structure of price dependence between different pork cuts, using the copula methodology. Retail prices from centre cut-bone in chops, boneless chops, and other pork chops have been selected as a case study.

The estimated lower and upper tail dependence coefficients are not statistically significant in all three pairs. The results suggest that retail price booms (crashes) in one cut will 

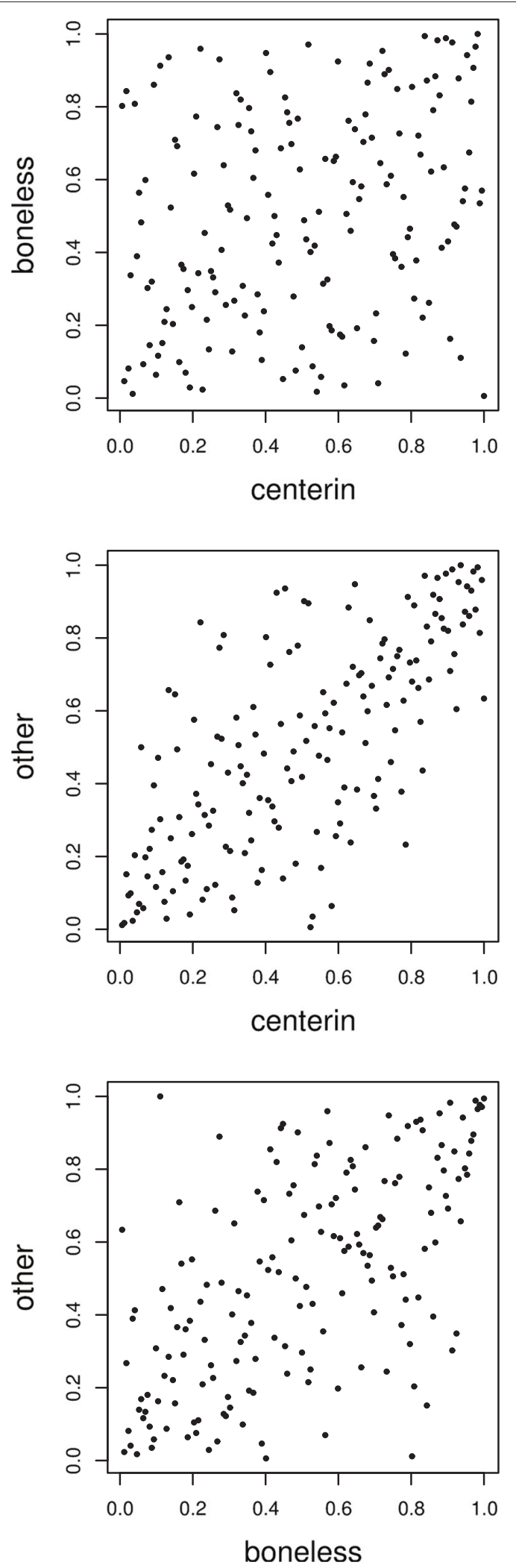

Figure 2 Scatter plots of pork cuts copulas: center cut - bone in chops (centerin), boneless chops (boneless), and other pork chops (other). 
Table 2 Results from copula parameter estimation for different pairs of pork cuts

\begin{tabular}{llllll}
\hline $\begin{array}{l}\text { Pork cuts } \\
\text { (chops) pairs }\end{array}$ & $\begin{array}{l}\text { Selected } \\
\text { Copula }\end{array}$ & Parameters & Kendall's $\tau$ & $\lambda_{L}$ & $\lambda_{U}$ \\
\hline Bone in/boneless & Student - t & $\begin{array}{l}\hat{\theta_{1}}=0.262^{* * *} \\
(0.077)\end{array}$ & $\begin{array}{l}0.169^{* * *} \\
(0.051)\end{array}$ & 0.007 & 0.007 \\
& & & & $(0.033)$ \\
& & & & \\
& & $(4.457)$ & $0.033)$ \\
Bone in/other & Frank & $\hat{\theta}=6.185^{* * *}$ & $0.523^{* * *}$ & 0 & 0 \\
& & $(0.639)$ & $(0.031)$ & - & - \\
Boneless/other & Frank & $\hat{\theta}=4.767^{* * *}$ & $0.441^{* * *}$ & 0 & 0 \\
& & $(0.615)$ & $(0.040)$ & - & - \\
\hline
\end{tabular}

${ }^{* * *}$ denotes statistically significant at $1 \%$ level or less.

not be associated with retail price booms (crashes) in a different cut. This can be an indication that given identifiable differences between specific pork cuts, sellers at the retail level don't adopt different pricing strategies when market conditions change. Thus, there is no evidence of asymmetric price responses between the pairs of pork cuts considered in this study.

\section{Endnotes}

${ }^{a}$ For simplicity we consider the bivariate case. The analysis, however, can be extended to a $p$-variate case with $p>2$.

${ }^{\mathrm{b}} \mathrm{ARMA}-\mathrm{GARCH}$ models are commonly used to obtain filtered data in empirical studies of dependence among random processes with copulas (Aloui et al. 2013; Brechmann and Schepsmeier 2013; Czado et al. 2012; Patton 2012; Serra and Gil 2012).

${ }^{\mathrm{c}}$ The Box-Pierce and the autoregressive conditional heteroskedasticity-Lagrange multiplier (ARCH-LM) tests were applied to the filtered data at various lag lengths. The estimated p-values reveal that residuals are free from autocorrelation and from ARCH effects.

Competing interests

The authors declare that they have no competing interests.

\section{Authors' contributions}

DP conceived the research idea, AS conducted the empirical and computational analysis, DP drafted the manuscript, Both authors read and approved the final manuscript.

Received: 25 September 2014 Accepted: 31 December 2014

Published online: 29 January 2015

\section{References}

Aloui R, Shawkat H, Nguyen DK (2013) A time-varying copula approach to oil and stock market dependence: The case of transition economies. Energy Econ 39:208-221

Boyd MS, Brorsen BW (1988) Price asymmetry in the us pork marketing channel. North Cent J Agric Econ 10(1):103-109 Brechmann EC, Schepsmeier U (2013) Modeling dependence with c-and d-vine copulas: The r-package cdvine. J Stat Softw 52:1-27

Cherubini U, Luciano E, Vecchiato W (2004) Copula methods in finance. Wiley \& Sons Ltd, Chichester, England

Chen X, Fan Y (2006) Estimation of copula-based semiparametric time series models. J Econometrics 130:307-335

Czado C, Schepsmeier U, Min A (2012) Maximum likelihood estimation of mixed c-vines with application to exchange rates. Stat Model 12(3):229-255

Emmanouilides C, Fousekis P, Grigoriadis V (2013) Price dependence in the principal eu olive oil markets. Span J Agric Res 12:3-14

ERS-USDA (2014) Retail prices for beef, pork, poultry cuts, eggs, and dairy products. http://www.ers.usda.gov/dataproducts/meat-price-spreads.aspx. Accessed 30 June 2014

Goodwin BK, Harper DC (2000) Price transmission, threshold behavior, and asymmetric adjustment in the us pork sector. Jgric Appl Econ 32(3):543-554

Jaworski P, Durante F, Hardle WK (eds) (2010) Copula theory and its applications. Lescture notes in statistics. Springer Science+Business Media, Inc.

Nelsen RB (2006) An introduction to copulas. Springer series in statistics, 2nd edn. Springer Science+Business Media, Inc. 
Patton AJ (2012) A review of copula models for economic time series. J Multivariate Anal 110:4-18

Qiu F, Goodwin BK (2012) Asymmetric price transmission: a copula approach. In: 2012 Annual Meeting, August 12-14,

2012. Agricultural and Applied Economics Association, Seattle, Washington. http://purl.umn.edu/124906

Reboredo JC (2012) Do food and oil prices co-move? Energy Policy 49:456-467

Serra T, Gil JM (2012) Biodiesel as a motor fuel price stabilization mechanism. Energy Policy 50:689-698

Sklar A (1959) Fonctions de repartition a n dimensions et leurs marges. Publicatons de L'Institut Statistique de L'Universite de Paris 8:229-231

Submit your manuscript to a SpringerOpen ${ }^{\odot}$ journal and benefit from:

- Convenient online submission

- Rigorous peer review

- Immediate publication on acceptance

- Open access: articles freely available online

- High visibility within the field

- Retaining the copyright to your article

Submit your next manuscript at $>$ springeropen.com 